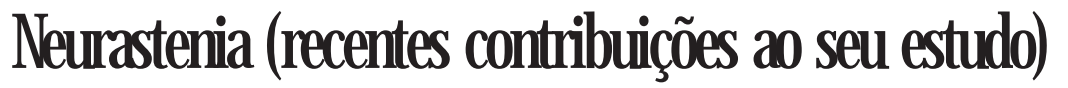

\author{
Dom Justino, O.S.B. (Doctor Med.)
}

Arquivos Brasileiros de Psiquiatria, Neurologia e Medicina Legal, Rio de Janeiro, n.3-4, 1907, p.388-395

\section{u u UUU}

No número de Junho da "Terapie der Gegenwart”, publicado pelo Professor Dr. Klemperer, de Berlim, o conselheiro Professor Dr. Wilhelm Erb, de Heidelberg, trata em artigo substancioso da moléstia acima dita; é interessante acompanhar as opiniões do célebre patologista.

Relativamente à natureza da neurastenia, pensa o Prof. Erb não se tratar de um mal psicogênico neste sentido, que toda a doença ou pelo menos os principais sintomas se desenrolem na via psíquica, apesar de apresentarem muitos neurastênicos numerosos sintomas psíquicos.

Tudo, pelo contrário, faz crer que se deva tratar de perturbações de nutrição, moleculares, muito delicadas - para nós até hoje inexplicáveis - e que nós costumamos chamar perturbações funcionais.

No quadro sintomático da neurastenia, encontramos em alto grau uma fraqueza anormal, um cansaço e esgotamento, ao mesmo tempo que uma sensibilidade aumentada. A origem da moléstia tem quase sempre por causa os excessos de esforços e a grande perda de energia do sistema nervoso, muitas vezes já hereditariamente enfraquecido - o "surmenage" dos franceses.

O tratamento deve ter início com a profilaxia.

Desde o berço é preciso empregar todos os meios no sentido de auxiliar o corpo; endurecendo$\mathrm{o}$, tornando-o resistente como o aço. A alimentação deve ser farta, devendo constar principalmente de gordura, ovos, leite, amiláceos, óleo de fígado de bacalhau, etc. Deve-se afastar as bebidas alcoólicas, o café, o chá; tomar lavagens frias e banhos; permanência constante e movimentos ao ar livre; jogos; absorver o ar dos bosques, das montanhas e do mar; evitar todas as excitações prematuras, seja as da inteligência, seja as da vida psíquica ou do instinto sexual; procurar ter sono suficiente, etc. No tempo escolar, deve-se ter em mira uma higiene racional, no mais amplo sentido do termo: é preciso não trabalhar demasiadamente e sim estabelecer o equilíbrio entre as horas de trabalho, as de repouso e as de movimento. Na época da puberdade é dever vigiar as tendências sexuais da nossa mocidade, e lutar contra a anemia e a clorose, etc. Na vida profissional tem um grande papel a divisão razoável entre o trabalho e o descanso, evitando-se excessos quanto ao primeiro, bem como "in Baccho et Venere".

N.E. - Sobre este artigo, ver "Neurastenia", de Rafaela Teixeira Zorzanelli, neste número de História, Ciências, Saúde Manguinhos. 
Uma vez que a moléstia se manifestar, deve-se atender à indicação causal, que é diferente para cada caso: Evitar, o que for diariamente prejudicial, o "surmenage", uma vida agitada e inquieta; não exercer a sua profissão por algum tempo; abster-se das bebidas supérfluas e nocivas; regular a convivência sexual; tomar medidas contra a anemia, a dispepsia e a má alimentação. Os meios a empregar para suprimir a doença, consistem pois num regime bem roborante. Há muitos caminhos para se chegar a esse resultado. Na primeira linha está a regularização da dieta e o modo de viver do doente; depois lavagens diárias com água fresca e frequentes banhos, mornos ou frios.

Quanto possível ficar ao ar livre e os doentes em estado grave podem mesmo deitados se expor à influência benéfica da atmosfera.

Regular os movimentos volitivos dos doentes é uma das principais questões do tratamento, $\mathrm{e}$ para isso servem: a ginástica em casa, os passeios, a subida em montanhas, o remo, o exercício em bicicleta, o lawn-tennis, a equitação, etc.; mas convém notar que, para aplicação desses recursos, é necessário sempre e em tudo: "individualizar", sendo preciso para isso muita experiência e grande cautela.

Além disso, é de grande alcance o regulamento e a dietética do trabalho mental e das funções profissionais.

Têm a primazia na cura da neurastenia, hoje em dia, os meios curativos chamados físicos como sejam: "a aeroterapia, a hidroterapia, a eletroterapia, a balneoterapia". O tratamento essencialmente medicamentoso constitui um poderoso auxiliar e consiste principalmente em ministrar tônicos.

Mas levando-se em conta esses processos assinalados - o físico, o dietético, o tônico -, veremos, que existe um outro mais importante ainda, consistindo no tratamento que chamaremos "psíquico". Ele forma um fator indispensável para o bom êxito e precisa ser exercitado com um cuidado especial e um tato delicado. Sem a influência psíquica, a cura não se realizará radicalmente, falhando quase por completo os outros meios empregados.

Ao terminar seu instrutivo artigo o Professor Dr. Erb fornece ao médico alguns conselhos dignos de consideração, que podemos resumir assim:

"Julgar sérios todos os casos de neurastenia; bem ponderar que aqueles que se procuram curar estão realmente doentes: examinar o doente com o máximo cuidado e assim se certificar de que o mal é certamente neurastenia e não causado por outro defeito orgânico; captar a confiança do doente; bondosamente aceitar as suas queixas com discrição e tato e deste modo fazer desaparecer os seus receios; em todos os casos individualizar e conseguir com paciência, perseverança e sequência o plano da cura".

Com estes princípios do experimentado clínico da "Alma Mater" de Heidelberg, concorda quase em todos os pontos um livro, que nestes últimos tempos nos tem ocupado a atenção e sobre o qual nos será ainda permitido dizer alguma coisa:

"Neurastenia", natureza, cura e profilaxia, pelo Dr. Alfredo Baumgarten, médico clínico da Baviera.

A mencionada obra obteve em pouco tempo quatro edições e foi em geral bem aceita pela crítica alemã. Naturalmente houve também quem a combatesse; mas isto tem a sua explicação no fato de que Baumgarten é o médico dirigente da "Kneipp Centrale" em Woerishofen.

Porém, para o médico, livre de preconceitos, esforçado e progressista, que sabe estabelecer a diferença entre o joio e o trigo - são dignos de aceitação os princípios e as indicações, que por 
um lado se harmonizam com uma autoridade igual à de Erb e por outro lado surgem da pena dum homem de ciência que dispõe dum rico material de casos de moléstias nervosas e este de todos os países do mundo, pondo assim ao nosso alcance um verdadeiro tesouro duma doutrina experimentada acerca da neurastenia.

O Professor Bier exige na sua obra "Hiperaemia als Heilmittel" - que um ponto de vista "teleológico" seja necessário, salutar e justo ao médico, e também indispensável à observação das coisas na natureza viva. Para prejuízo nosso, reconhecemos tarde demais, o que os outros, que nada de comum tinham conosco e às vezes com pouca ciência, já cultivaram empiricamente. Quando os curandeiros como cogumelos surgiram da terra e se encheram, sem o menor escrúpulo, com o dinheiro daqueles, que só tinham em mira a saúde; quando isso acontecia, a medicina apaticamente tudo observava e, só mais tarde, reagiu, reconhecendo ser ela a única capaz, pelo valor de sua ciência, de intervir por seus legítimos representantes - os médicos, depositários de ciência e de inteligência.

Estamos assim convencidos de que muitos estudarão com prazer esta obrinha - aqueles, "sine ira et studio" verificarão os resultados práticos e verídicos na cura da neurastenia, como nos faz ver Baumgarten. Faremos votos, para que ela encontre bom agasalho em nossas rodas médicas, onde se observa um espírito de alta cultura científica e um tão acendrado amor pelas coisas da medicina. ${ }^{1}$

Não nutrimos dúvida sobre a sua aceitação, porquanto ela não se destina somente aos médicos, mas também aos sacerdotes, pedagogos, filósofos e economistas nacionais, enfim a todos aqueles que trabalham pelo espírito.

Em poucas palavras tratando-se da atraente obra científica, tomamos a liberdade de salientar do prefácio à primeira edição, as observações do Dr. Baumgarten que tem por si uma clínica prática de 16 anos, sendo que os últimos 10 em Wörishofen, e esta clínica é tão grande relativamente à neurastenia como poucos médicos poderão alcançar. O autor afasta-se por vezes dos seus colegas, colocando-se em ponto de vista diferente relativamente a certas questões, mas isso não quer dizer que suas asserções sejam falsas.

O livro começa por uma brilhante e instrutiva exposição sobre "nervosidade" e "força dos nervos", entra depois no tema particular sobre a neurastenia. Depois de algumas explicações gerais sobre a importância, origem e noção de neurastenia, estabelece ele duas formas para ela: uma aguda e outra crônica. Da forma crônica encontram-se, naturalmente, observações mais amplas, e o autor explica, então, em capítulos detalhados, as manifestações físicas e psíquicas.

A esta parte segue-se o trecho "O que conduz à neurastenia?" - Uma parte da obra excepcionalmente interessante é constituída pelos numerosos casos clínicos de sua observação, casos estes que nos dão ensejo de encontrar tipos de todas as nacionalidades.

"Cura da neurastenia" - Esta se obtém pelo concurso de dois tratamentos - o físico e o psíquico, e, portanto, éa manifestação doentia que necessita de dois tratamentos: O médico, que unicamente esperar ou tiver esperado pelos efeitos dos medicamentos administrados aos neurastênicos sofrerá bastantes decepções e continuará a sofrê-las constantemente.

\footnotetext{
${ }^{1}$ Acaba de aparecer a tradução francesa condensada desta obra graças ao Dr. Bonnayné, de Lyon: La neurasthénie, sa nature, sa guérison, sa prophylaxie.
} 
O tratamento psíquico se pode resumir no seguinte axioma: "Fac - trabalha; spea - tem esperança."

Neurastênicos são quase sempre indivíduos cuja compreensão da vida falhou, indivíduos que perderam a crença na energia própria; que não têm mais interesse no mundo e se deixam levar, sem reagir, pelo mar da vida, como um batel sem leme à mercê das ondas... É por este motivo que a principal preocupação do médico deve ser incutir novamente no doente a visão verdadeira, prática e sã da vida, que se verifica sucessivamente pela influência do "querer, do pensar e do agir".

O tratamento físico tem por base os fatores de cura já conhecidos: "Água, ar, sol e clima?".

E neste campo não se encontra o médico ou o povo, mas o médico $e$ o povo juntos, cada qual a seu modo, em caminho para Roma - não para Canossa! O médico deve fazer justiça ao sentimento da alma popular e seguir entre o povo, instruindo-o, e não lançando sobre seus atos o véu Hipocrático.

À terapia bem estudada segue-se um capítulo sobre a "Profilaxia" e no fim há uma explanação instrutiva sobre a neurastenia, concernente à nossa mocidade, e onde há conselhos destinados aos pais, professores, educadores, superiores de institutos, como também aos profissionais.

"Para a verdade um caminho!" é a divisa escolhida por Baumgarten para a $3^{\underline{a}}$ edição do seu livro. Se em alguma parte pode ter curso este conceito, nunca se aplicará, por certo, melhor do que na Profilaxia e Terapêutica do mal neuropático dos seres humanos de hoje - mal que cresce assustadamente. A neurastenia é um dos mais assombrosos e mortais perigos do XX século que estão vindo sobre nós, por trazer tanto prejuízo à vida, à energia e ao trabalho da humanidade.

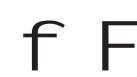

